\title{
Unit per Kilogram per Minute
}

National Cancer Institute

\section{Source}

National Cancer Institute. Unit per Kilogram per Minute. NCI Thesaurus. Code C73779.

An arbitrary unit of substance rate expressed in unit(s) per kilogram per period of time equal to sixty seconds. 